\title{
1 The development of a weak anion micro-capillary film for protein \\ 2 chromatography
}

3 A. J. M. Kouyoumdjian, R. A. Lazar, N. K. H. Slater*

4 *Corresponding author. Tel.: +44 (0) 1223 762953; Fax: +44 (0) 1223334796

5 Email address: nkhs2@cam.ac.uk (N. Slater)

6 Department of Chemical Engineering and Biotechnology, University of Cambridge, Pembroke Street,

7 Cambridge CB2 3RA, United Kingdom

9 Abstract

10 In this study, the surface of a microporous walled micro-capillary film (MMCF) was modified into a weak anion exchanger by coupling cyanuric chloride and 2diethylaminoethylamine (DEAE) to the ethylene-vinyl alcohol (EVOH) matrix. Fourier transform infrared spectroscopy (FTIR) measurements of modified and unmodified MMCFs confirmed the addition of a triazine ring and DEAE onto the membrane. Binding of bovine serum albumin (BSA) at pH 7.2 was found to follow a Langmuir isotherm with a maximum equilibrium binding of $12.4 \mathrm{mg} \mathrm{BSA} / \mathrm{mL}$ adsorbent and $8.2 \mathrm{mg} \mathrm{BSA} / \mathrm{mL}$ adsorbent under static and flow conditions, respectively. The ion exchange capacity, determined by Mohr's titration of chlorine atoms displaced from the functionalised surface, was found to be $195 \pm$ $21 \mu \mathrm{mol} \mathrm{Cl}-/ \mathrm{mL}$ of adsorber, comparable to commercial ion exchangers. BSA adsorption onto the ion exchanger was strongly $\mathrm{pH}$-dependant, with an observed reduction in binding above $\mathrm{pH}$ 8.2.

Frontal experiments of a BSA (5 mg/mL) and lysozyme (5 mg/mL) mixture demonstrated successful separation of BSA from lysozyme at more than $97 \%$ purity as verified by sodium dodecyl sulfate polyacrylamide gel electrophoresis (SDS-PAGE). Separation between similarly charged anionic molecules was also achieved using BSA (5 mg/mL) and herring sperm DNA (0.25 mg/mL). BSA was extracted at 100\% purity, demonstrating the ability of MMCF-DEAE to remove significant DNA contamination from a protein solution. These experiments highlight the potential for MMCFs to be used for fast protein purification in preparative chromatography application.

Key words: weak anion-exchange, chromatography, micro-capillary films, membranes, 


\section{Introduction}

The pharmaceutical industry has progressively shifted its focus from small chemical drugs towards the use of large biomolecules such as antibodies. In order to scale-up the manufacture of biopharmaceuticals and produce them at a greater efficiency, product-specific titres have increased steadily over the past three decades from less than $0.5 \mathrm{~g} / \mathrm{L}$ in the early 1990s to values in excess of $3 \mathrm{~g} / \mathrm{L}$ for newer processes, with $7 \mathrm{~g} / \mathrm{L}$ and above being the new top-end industry target [1]. This order of magnitude increase has moved the production bottleneck downstream, towards the product purification stage where technologies with greater throughput and faster separation capabilities are needed.

Membranes have been demonstrated to be viable chromatography support for rapid protein purification on account of the high superficial velocities that can be attained without performance penalties [2]. As convective mass transport is the dominant mode by which separations occur, flowrate independent binding can be achieved. Membranes have been used in a wide range of chromatographic operations such as the purification of plasmid DNA using anion exchange [3], the capture of IgG using Protein A affinity chromatography [4] and the purification of retroviruses [5]. Membrane adsorbers still suffer from several disadvantages with respect to packed beds including their historically poor binding capacity [6] which limit their use in industry.

Micro-capillary films (MCFs) aim to provide a low-cost technology for protein separations [7]. Composed of a continuous capillary array embedded into an ethylene-vinyl alcohol (EVOH) film matrix, these membranes have the potential for use in direct capture of proteins from unfiltered cell lysate. MCFs can be extruded as a non-porous (NMCFs) film using melt extrusion [8] or a porous (MMCFs) film using non-solvent induced phase separation (NIPS) [9]. Benefits of this technology include its ease of manufacture and scale-up (tubular configuration), its low cost ( 50 pence/metre for MCF manufacture) [7] and the high superficial velocities through the membrane lumen which can be attained (greater than 5000 $\mathrm{cm} / \mathrm{h}$ ) [10]. Moreover, the hydroxyl-rich nature of the polymer allows for a wide-range of ligands to be coupled to MCFs for chromatography applications. Q-functionalised MCFs have been successfully used to remove lentivirus from unfiltered culture media containing suspended solids [11] and strong cation SP- membranes have been used to separate 
cytochrome-c and lysozyme [7], lysozyme from BSA [10] and to monitor at-line IgG aggregates in bioreactors [12].

The objective of this paper was to develop and demonstrate a weak MMCF ion exchanger to complement existing MMCF chemistries. The MMCF was modified with 2diethylethylenediamine (DEAE) and the performance of the exchanger was characterised. The separation of BSA from lysozyme was used to determine the ability of MMCFs to separate model proteins of opposite charge at $\mathrm{pH} 7.2$ and, the separation of BSA from herring sperm DNA was performed to highlight the potential use of MMCF-DEAE for residual DNA clearance.

\section{2.}

\section{Materials and methods}

\section{1}

\section{Chemicals used}

Ethylene vinyl alcohol (EVOH) copolymer with 68 mol\% vinyl alcohol was purchased from Kuraray (Hattersheim, Germany). N-methyl-2-pyrrolidine (NMP), polyvinyl-pyrrolidone (PVP, average molecular weight $360 \mathrm{kDa}$ ), glycerol, bovine serum albumin (BSA, pI 5.3, MW $66.4 \mathrm{kDa}$ ), tris(hydroxy- methyl)aminomethane (Tris), hydrochloric acid ( $\mathrm{HCl}$ ), sodium hydroxide $(\mathrm{NaOH})$, sodium chloride $(\mathrm{NaCl})$, crystalline chick-egg lysozyme (pI 11, MW 14.3 $\mathrm{kDa}$ ), sodium phosphate monobasic $\left(\mathrm{NaH}_{2} \mathrm{PO}_{4}\right)$, 2-diethylaminoethylamine (DEAE), Bradford reagent and cyanuric chloride were purchased from Sigma Aldrich (St. Louis, MO, USA).

2.2

\section{Membrane manufacture}

MMCFs were produced using protocols described previously [9] [10]. Briefly, polymer solutions containing 15/10/75 wt.\% EVOH/PVP/NMP were wet extruded through a 19nozzle die of capillary size $0.5 \mathrm{~mm}$, followed by non-solvent induced phase separation (NIPS) in a water bath. Membranes were then stored in a 50/50 v/v glycerol-water solution for long term processing.

Gravimetric analysis was used to determine the column volume (CV) of the membranes so that the binding capacities obtained could be normalised and compared with commercial columns. The column volume, was defined as the total volume from the microporous walls and central capillaries of the film and was found to be $1.06 \pm 0.09 \mathrm{~mL}$ for a $20 \mathrm{~cm}$ MMCF 
section (dried weight, $164 \pm 5 \mathrm{mg}$ ). A $20 \mathrm{~cm}$ MMCF length was used for this work as it had a convenient column volume $\sim 1 \mathrm{~mL}$.

\section{3}

BET and mercury intrusion porosimetry

$\mathrm{N}_{2}$ adsorption was measured at 77.4 K using a Micromeritics ASAP 2020 instrument (Norcross, GA, USA) to determine the membrane surface area using Brunaeur-Emmett-Teller (BET) theory. The membrane pore surface area and pore size distribution (PSD) was measured using a Micromeritics AutoPore IV 9500 porosimeter (Norcross, GA, USA) up to a final pressure of 2000 bar.

MMCF samples were vacuum dried overnight at $150^{\circ} \mathrm{C}$ prior to $\mathrm{N}_{2}$ adsorption and porosimetry measurements.

\section{4}

\section{Chemical modification of MMCFs with DEAE}

The coupling of 2-diethylaminoethylamine (DEAE) onto the MMCF backbone was achieved using a modified batch protocol from McCreath et al. [13]. Briefly, a MilliQ washed membrane (25 cm, dry weight $205 \pm 6 \mathrm{mg}$ ) was placed in $50 \mathrm{mM}$ ice cold cyanuric chloride in acetone $(40 \mathrm{~mL})$ solution under constant agitation for 30 minutes. DEAE (2.48 g, 0.02 moles) was added to a $0.5 \mathrm{M} \mathrm{NaH}_{2} \mathrm{PO}_{4}$ aqueous solution (36 mL), the final solution was at pH 9.6. Cyanuric chloride activated MMCF was added to the DEAE solution, heated overnight at $40^{\circ} \mathrm{C}$ then at $60^{\circ} \mathrm{C}$ for 5 hours. The membrane was subsequently washed with MilliQ (50 mL) for 30 minutes and reactivated with $0.5 \mathrm{M} \mathrm{NaOH}(40 \mathrm{~mL})$ for 30 minutes.

The chemical modification is summarised in Fig. 1.

\section{5}

\section{Fourier transform infrared spectroscopy of MMCFs}

Fourier transform infrared spectroscopy (FTIR) was used to determine the presence of a cyanuric chloride ring and DEAE on the MMCF membrane. Spectra were collected using a Thermo Nicolet Nexus 870 spectrometer (Waltham, MA, USA) as the average of 32 scans with a wavenumber resolution of $4 \mathrm{~cm}^{-1}$ in the $600-4000 \mathrm{~cm}^{-1}$ range. As a control, unmodified MMCF was compared to MMCF-DEAE and spectra were normalised to the common $\mathrm{CH}_{2}$ vibration peak at $2852 \mathrm{~cm}^{-1}$. 
2.6

\section{Ion exchange capacity measurement}

The ion exchange capacity was determined using a modified protocol from Karas et al. [14]. Briefly, 20 sections of $1 \mathrm{~cm}$ MMCF-DEAE (dry weight $164 \pm 5 \mathrm{mg}$ ) were regenerated in 1 $\mathrm{M} \mathrm{NaOH}$ (40 mL) for 30 minutes prior to a 1 hour step in $1 \mathrm{~N} \mathrm{HCl} \mathrm{(50} \mathrm{mL).} \mathrm{After} \mathrm{two} \mathrm{MilliQ}$ wash steps (30 minutes each), the MMCF-DEAE segments were placed overnight in $0.1 \mathrm{M}$ $\mathrm{NaNO}_{3}(40 \mathrm{~mL})$ solution under agitation to displace $\mathrm{Cl}^{-}$ions from the modified membrane into the supernatant. Mohr's titration was used to titrate the $\mathrm{Cl}^{-}$in solution with $0.1 \mathrm{M} \mathrm{AgNO}_{3}$ and to determine the ion exchange capacity of the membrane. $0.25 \mathrm{M} \mathrm{K}_{2} \mathrm{CrO}_{4}(1 \mathrm{~mL})$ was used to indicate when all the $\mathrm{Cl}^{-}$had been exhausted from the supernatant.

Experiments were repeated in triplicate with unmodified MMCF used as a control.

$$
2.7
$$

Adsorption isotherm of BSA onto the membrane

Stock solutions of BSA at concentrations $0.25,0.5,1,2,3,5$ and $10 \mathrm{mg} / \mathrm{mL}$ were prepared in $20 \mathrm{mM}$ Tris-HCl pH 7.2 buffer to determine the adsorption behaviour of protein onto the membrane.

4 sections of $1 \mathrm{~cm}$ MMCF-DEAE (dry weight $33 \pm 1 \mathrm{mg}$ ) were left for 48 hours under agitation in $5 \mathrm{~mL}$ protein solution to reach equilibrium. To remove unbound protein from the membrane surface, the supernatant was replaced with $3 \mathrm{~mL}$ of buffer and the membrane was centrifuged at 5000g for 12 minutes. Both supernatants were then combined and a Bradford assay was used following the protocol provided by the supplier. Measurements of the remaining BSA in the supernatant were performed at UV $595 \mathrm{~nm}$ using a BMG Labtech SPECTROstar Nano (Allmendgruen, Germany). The amount of protein bound onto the MMCFs was determined by mass balance and, all experiments were repeated in triplicate. 2.8

Time course binding studies 4 sections of $1 \mathrm{~cm}$ MMCF-DEAE membranes were immersed in $1 \mathrm{mg} / \mathrm{mL}$ BSA in Tris-HCl $\mathrm{pH} 7.2(5 \mathrm{~mL})$ and were used to determine the binding of BSA onto the membrane as a function of time. $50 \mu \mathrm{L}$ samples were taken at $\mathrm{t}=0,0.5,1,2,3,6,8,12,16,24,32$ and 48 hours and quantified using a Bradford assay.

Experiments were repeated in triplicate and unmodified MMCF was used as a control. 
158 Extruded membranes were encased in $8 \mathrm{~mm}$ FEP tubing (Kinesis Ltd, St. Neots, UK) using 159 epoxy glue (Araldite ${ }^{\circledR}$, Cleveland, OH, USA), trimmed to $20 \mathrm{~cm}$ in length and fitted with 160 Upchurch 1/4 inch HPLC connectors to be attached to an ÄKTA FPLC system (GE

161 Healthcare Life Sciences, Uppsala, Sweden) as described by Mandal et al. [10]. Fig. 2 shows a schematic representation of the MMCF column module and a SEM image of an MMCF cross-section. BSA solutions of 1, 5, 10, 20 and $40 \mathrm{mg} / \mathrm{mL}$ in $20 \mathrm{mM}$ Tris- $\mathrm{HCl} \mathrm{pH} 7.2$ (running buffer) were loaded to saturation onto the membrane to determine the binding profile of MMCFDEAE under flow (dynamic) condition. The flowrate was chosen to be $1 \mathrm{~mL} / \mathrm{min}$ ( 56.6 $\mathrm{CV} / \mathrm{h})$, flowing through the lumen of the membrane. Elution was performed with a step gradient of $1 \mathrm{M} \mathrm{NaCl}$ in running buffer.

Eqs. (1) was used to calculate the mass of BSA eluted at increasing loading concentration.

Mass eluted $(m g)=\frac{C_{\text {inj }}\left(m g m L^{-1} \times \text { Elution Area }(m A U m L)\right)}{100 \% \text { Saturation height }(m A U)}$

173 Where $\mathrm{C}_{\mathrm{inj}}$ is the concentration of protein used at injection.

174 The data was fitted to a Langmuir isotherm adsorption model, described according to Eqs. (2) derived from adsorption-desorption kinetics:

$176 \quad q=q_{\max } \frac{\alpha C_{i n j}}{1+\alpha C_{i n j}}$

177 With q being the mass bound at all $\mathrm{C}_{\mathrm{inj}}$, $\mathrm{q}_{\max }$ the equilibrium binding capacity and $\alpha$ the 178 Langmuir adsorption constant.

181 Frontal analysis experiments using BSA were conducted from $\mathrm{pH} 6.2$ to $\mathrm{pH} 9.2$ to determine $\mathrm{pH}$ dependency of the membrane in flow condition. A $20 \mathrm{mM}$ Tris- $\mathrm{HCl}$ running buffer was used and samples were eluted in running buffer containing $1 \mathrm{M} \mathrm{NaCl}$. 
The column was equilibrated for $5 \mathrm{CV}$ at a flowrate of $1 \mathrm{~mL} / \mathrm{min}$, then continuously loaded through the lumen of the membrane with BSA $(10 \mathrm{mg} / \mathrm{mL})$ until $100 \%$ column saturation as determined by UV absorbance measurements at $280 \mathrm{~nm}$. The column was washed with running buffer for $15 \mathrm{CV}$ followed with a step elution over $10 \mathrm{CV}$. The column was reequilibrated for $10 \mathrm{CV}$ between each run.

Experiments were repeated in triplicate and the mass of BSA eluted was calculated using Eqs. (1).

The effect of flowrate on binding was determined using $100 \mu \mathrm{L}$ pulse injections of BSA (5 mg/mL) onto MMCF-DEAE. The capture (\%) was calculated using Eqs. (3):

Capture $(\%)=\frac{\text { Elution Area }(m A U \mathrm{~mL})}{\text { Elution Area }(m A U \mathrm{~mL})+\text { Flowthrough Area }(m A U \mathrm{~mL})} \times 100$

Flowrates between $0.1 \mathrm{~mL} / \mathrm{min}$ and $10 \mathrm{~mL} / \mathrm{min}$ were tested to keep the pressure drop below 1.5 MPa which is the limiting upper pressure for the column adaptors.

2.12

Lysozyme and BSA separation

A subtractive separation of BSA from lysozyme was tested on MMCF-DEAE using $5 \mathrm{mg} / \mathrm{mL}$ lysozyme and $5 \mathrm{mg} / \mathrm{mL}$ BSA loaded through the membrane lumen at $1 \mathrm{~mL} / \mathrm{min}$ until $100 \%$ column saturation. $1 \mathrm{~mL}$ fractions of the flowthrough and elution were collected to assess peak purity using sodium dodecyl sulphate polyacrylamide gel electrophoresis (SDS-PAGE).

Fractions (diluted tenfold) were loaded onto NuPAGE Novex 4-12\% Bis-Tris pre-cast gels (Invitrogen, Paisley, UK), per the manufacturer's instructions. Novex Sharp pre-stained protein standards (Invitrogen, Paisley, UK) were used as molecular weight (MW) markers. The XCell SureLock Mini-Cell electrophoresis system (Invitrogen, Paisley, UK) was used at $200 \mathrm{~V}$ for 35 min with MES SDS running buffer. Coomassie staining was performed using SimplyBlue SafeStain (Invitrogen, Paisley, UK) following the manufacturer's protocol.

Experiments were repeated on an unmodified MMCF as a control to determine the presence of non-specific protein binding to the membrane matrix (see supplementary materials).

\subsection{3}

\section{Herring sperm DNA and BSA separation}

The ability to separate two anionic molecules was tested using $100 \mu \mathrm{L}$ injections of BSA (5 $\mathrm{mg} / \mathrm{mL})$ and herring sperm DNA $(0.25 \mathrm{mg} / \mathrm{mL})$ onto a $20 \mathrm{~cm}$ MMCF-DEAE column. A two- 
step elution at $0.25 \mathrm{M} \mathrm{NaCl}$ and $1 \mathrm{M} \mathrm{NaCl}$ was used to separate BSA from DNA. UV measurements were performed at $254 \mathrm{~nm}$ and $20 \mathrm{mM}$ Tris-HCl pH 7.2 was used as the running buffer at $1 \mathrm{~mL} / \mathrm{min}$.

To assess the purity of the elution peaks, the elution fractions were injected onto a commercial Mono Q 5/50 GL high-resolution Tricorn column (GE Healthcare Life Sciences, Uppsala, Sweden) following the protocol described in the supplementary materials.

3.

\title{
Results and Discussions
}

\author{
3.1
}

Surface characterisation of MMCFs: Nitrogen adsorption, mercury porosimetry and FTIR results.

Nitrogen adsorption onto an MMCF sample exhibited a type III isotherm [15] as shown in Fig. 3A and the BET surface area was calculated to be $8.95 \mathrm{~m}^{2} / \mathrm{g}$. The total pore area of 8.6 $\mathrm{m}^{2} / \mathrm{g}$ obtained from mercury porosimetry was found to agree well with $\mathrm{N}_{2}$ adsorption results and, a bimodal pore size distribution (PSD) centred at $1000 \mathrm{~nm}$ and $100000 \mathrm{~nm}$ in diameter (see Fig. 3B) was observed. Fig. 2A suggests that, the larger "pores" corresponded to the central capillaries, defects and macrovoids whereas the pores between $150 \mathrm{~nm}$ and $3000 \mathrm{~nm}$ were representative of the PSD within the membrane film.

FTIR spectra of unmodified MMCF and MMCF-DEAE revealed the presence of two additional peaks at $1578 \mathrm{~cm}^{-1}$ and $1547 \mathrm{~cm}^{-1}$ for MMCF-DEAE (see Fig. 4). These correspond to in-plane vibration of a triazine [16] and secondary amine N-H bend [17] respectively. This indicates that both triazine and DEAE were successfully coupled to the membrane.

\section{2}

\section{Characterisation of MMCF-DEAE in static conditions: ion exchange capacity and} protein binding isotherm.

The ion exchange capacity of the modified membrane was found to be $195 \pm 21 \mu \mathrm{mol} \mathrm{Cl}^{-}$ /mL, twice the reported value of McCreath et al [13] and comparable to commercial exchangers ( 0.11 to $0.16 \mathrm{mmol} \mathrm{Cl}^{-} / \mathrm{mL}$ medium for DEAE Sepharose Fast Flow [18] and 0.29 to $0.35 \mathrm{mmol} \mathrm{Cl}^{-} / \mathrm{mL}$ medium for GE Capto DEAE [19]). 
244 Static binding data fit the Langmuir model well $\left(\mathrm{R}^{2}=0.98\right)$, suggesting monolayer binding of protein to active sites (see Fig. 5A). The equilibrium binding capacity was measured to be $\mathrm{q}_{\max }=12.4 \mathrm{mg}$ of BSA/mL of adsorbent, similar to the value reported in McCreath et al. of $9.7 \mathrm{mg} / \mathrm{mL}$ adsorbent for human serum albumin (HSA) onto perfluoropolymers [13] but more than an order of magnitude lower than that achieved with commercial membranes [20].

The binding of BSA onto MMCF-DEAE was found to increase linearly during the first 8 hours (see Fig. 6) prior to reaching a plateau at the 12 hour mark due to binding site saturation. After 24 hours, a maximum binding was reached of $10 \mathrm{mg} \mathrm{BSA} / \mathrm{mL}$ adsorbent, inline with the previously observed maximum binding of $10 \mathrm{mg} B S A / \mathrm{mL}$ adsorbent at $1 \mathrm{mg}$ BSA/mL loading (Fig. 5A).

\section{and the effect of $\mathrm{pH}$ and flowrate on binding}

By loading a $20 \mathrm{~cm}$ MMCF-DEAE column with BSA at varying concentrations from 1 $\mathrm{mg} / \mathrm{mL}$ to $40 \mathrm{mg} / \mathrm{mL}$, an equilibrium dynamic binding profile was obtained and fitted with a Langmuir equation (see Fig. 5B). The Langmuir model was found to fit the data well $\left(\mathrm{R}^{2}=\right.$ 0.99) but showed a $30 \%$ binding reduction compared to the equilibrium binding capacity (EBC) obtained under static condition, $8.2 \mathrm{mg} \mathrm{BSA} / \mathrm{mL}$ adsorber compared to $12.4 \mathrm{mg}$ BSA/mL adsorber. This has been observed previously [13] and was most likely a result of the larger mass transfer resistance present in small pores: under flow conditions, some binding sites were inaccessible to proteins due to the shorter residence times available for the analytes to diffuse into the membrane matrix.

The effect of pH on binding under flow condition is shown in Fig. 7. As the $\mathrm{pH}$ was increased from pH 6.2 to 9.2, a sharper breakthrough curve (Fig. 7A) during the loading step was obtained indicating that less mass was bound to the column. This was verified in the elution step (Fig. 7B) where, the largest elution area was obtained at $\mathrm{pH} 6.2$ corresponding to a binding of $7.7 \mathrm{mg} \mathrm{BSA} / \mathrm{mL}$ adsorbent. Further increase in $\mathrm{pH}$ resulted in diminished binding and, at pH 9.2 the elution peak was below detection limit (Fig. 7C). This behaviour was in-line with what was expected from a weak anion exchanger and the known pKa value of the tertiary amine group of DEAE 7.1 [21]. At $\mathrm{pH}>\mathrm{pKa}$, the protonation of the binding site was diminished and loss of charge occurred. 
The breakthrough curves at all pHs had a characteristic S-shape corresponding to non-ideal protein breakthrough. The elution peaks of Fig. 7B show an asymmetrical elution profile with a long tail (greater than $5 \mathrm{CV}$ ) which would suggest that long diffusion times are needed to elute analytes trapped within the smaller pores of the matrix and within the membrane dead volume. It is likely that this non-ideality in flow was a result of the non-uniform pore size within the membrane (see Fig. 3B) and channelling down the membrane bore which have been shown to increase peak broadening [22]. The pore size distribution introduces a range of different solute path length and a varying diffusion rate (eddy diffusion) from the stationary phase to the mobile phase resulting in band broadening [23].

The effect of flowrate on binding was determined using $100 \mu \mathrm{L}$ injections of BSA $(5 \mathrm{mg} / \mathrm{mL})$ applied onto an MMCF-DEAE column at flowrates ranging from $0.1 \mathrm{~mL} / \mathrm{min}$ to $10 \mathrm{~mL} / \mathrm{min}$ (superficial velocities between $330-33000 \mathrm{~cm} / \mathrm{h}$ through the MMCF lumen). Fig. 8 shows that increasing the flowrate led to an increase in flowthrough in the loading stage and a decrease in mass eluted. The capture decreased from $90 \%$ at $0.1 \mathrm{~mL} / \mathrm{min}$ to $63 \%$ at 10 $\mathrm{mL} / \mathrm{min}$ with a sharper drop between $0.1 \mathrm{~mL} / \mathrm{min}$ and $1 \mathrm{~mL} / \mathrm{min}$ (Fig. 8C). Increasing the flowrate above $1 \mathrm{~mL} / \mathrm{min}$ did not significantly reduce the capture of BSA but introduced peak broadening. Although membranes typically have flowrate independent binding [24], this result was not surprising on account of the flow operation chosen. By flowing the protein mixture in the axial direction, through the membrane lumen, instead of as a radial transmembrane flow, radial mass transport to the membrane was slow (the Reynolds number is $<<1$ ) and, at high flowrates, binding was reduced due to the decreased residence time between the mobile phase and stationary phase.

\section{4}

Proof-of-concept separations of cationic-anionic and anionic-anionic protein mixtures using MMCF-DEAE

The separation of BSA from a lysozyme containing mixture is shown in Fig. 9. It can be seen that BSA was successfully recovered at high purity as determined by SDS-PAGE analysis of the elution (Fig. 9B). A faint lysozyme band below the limit of quantification was observed in the elution suggesting non-specific protein binding. From the control experiment using unmodified MMCF (see supplementary materials), it is likely that the non-specific lysozyme was bound to the MMCF backbone and was estimated to be $\sim 0.2 \mathrm{mg}$ of lysozyme/mL of adsorber. Therefore, with the same amount of non-specific binding, a purity greater than 97\% BSA (on a weight basis) was obtained using MMCF-DEAE. The high 
molecular weight species observed in Fig. 9B were neglected in this analysis and most likely corresponded to dimers and trimers of BSA which have been found to persist even under denaturing conditions [25].

The separation of two anionic molecules, fish sperm DNA and BSA, onto an MMCF-DEAE column was tested using a two-step $\mathrm{NaCl}$ elution. As can be observed in Fig. 10C, two elution peaks were obtained. From the controls, Fig. 10A and Fig. 10B, the first elution corresponded to a BSA dominant peak and that the second elution was DNA dominant. Further analysis of the fractions collected with a commercial Mono Q 5/50 GL highresolution Tricorn column (see supplementary materials) indicated that the first peak was pure BSA and the second elution peak was $81 \%$ herring sperm DNA with a 19\% BSA contamination. The detection limit of herring sperm DNA was estimated to be $\sim 16 \mathrm{ng}$ of DNA (see supplementary materials), of similar order of magnitude with the regulatory requirements of less than $10 \mathrm{ng}$ of genomic DNA per therapeutic dose [26].

The mass of BSA recovered in the first elution peak was $0.38 \mathrm{mg}$ of BSA corresponding to a $77 \%$ capture. The low capture of BSA could be improved by loading the column at a lower flowrate, using longer MMCF columns, increasing the salt concentration in the first elution or reducing the injected protein concentrations.

4.

\section{Conclusions}

In this study, the versatility of MMCFs was demonstrated by successful modification of the matrix with a new DEAE chemistry for protein chromatography. A simple two-step chemical modification resulted in a weak anion exchanger, as verified by FTIR analysis.

Characterisation of the membrane showed an ion exchange capacity of $195 \pm 21 \mu \mathrm{mol} \mathrm{Cl}^{-}$ $/ \mathrm{mL}$ of adsorber, significantly higher than that reported in previous studies and comparable to commercial exchangers. However, the binding capacity of MMCF-DEAE of $12.4 \mathrm{mg}$ $\mathrm{BSA} / \mathrm{mL}$ of adsorber was found to be significantly lower than that of commercial columns. This indicates that the binding behaviour will have to be improved for any preparative use to be achieved. Increasing the number of capillaries within the membrane film or improving the chemical modification used could result in improved binding.

The proof-of-concept separation of BSA from lysozyme revealed that recovery of BSA at more than $97 \%$ purity could easily be achieved. The more complex separation of BSA and herring sperm DNA demonstrated future potential of resolving two negatively charged 

compounds using this system. $77 \%$ of the BSA injected was recovered free of detectable 341 impurity despite the large DNA load present in the feed mixture..

342 These results suggest that with proper optimisation, MMCFs could be used as low-cost 343 residual DNA clearance devices. 
364 Acknowledgements

365 Arthur Kouyoumdjian would like to thank Trinity College at the University of Cambridge for

366 its generous financial support of his PhD studentship.

367 The authors would like to acknowledge the help and the work of, Tian Tian with nitrogen

368 adsorption studies, Zlatko Saracevic with mercury intrusion porosimetry and Pierre Braeur

369 with FTIR measurements - all within the Department of Chemical Engineering and

370 Biotechnology at the University of Cambridge. Finally, the authors would like to thank Dr

371 Jeremy Skepper at the Cambridge Advanced Imaging Centre for his help in conducting the

372 SEM measurements.

373

374

375

376

377

378

379

380

381

382

383

384

385

386

387

388 


\section{References}

391 [1] R.A. Rader, E.S. Langer, Biopharmaceutical Manufacturing: Historical and future

392 trends in titers, yields, and efficiency in commercial-scale bioprocessing, 13 (2015).

393 [2] J. Thoemmes, M.-R. Kula, Membrane chromatography - an integrative concept in the downstream processing of proteins, Biotechnol. Prog. 11 (1995) 357-367.

[3] M.A. Teeters, S.E. Conrardy, B.L. Thomas, T.W. Root, E.N. Lightfoot, Adsorptive membrane chromatography for purification of plasmid DNA, 989 (2003) 165-173.

[4] C. Boi, V. Busini, M. Salvalaglio, C. Cavallotti, G.C. Sarti, Understanding ligandprotein interactions in affinity membrane chromatography for antibody purification., J. Chromatogr. A. 1216 (2009) 8687-96.

400 [5] D.J. McNally, D. Darling, F. Farzaneh, P.R. Levison, N.K.H. Slater, Optimised concentration and purification of retroviruses using membrane chromatography., J. Chromatogr. A. 1340 (2014) 24-32.

403 [6] J. Thömmes, M. Etzel, Alternatives to chromatographic separations., Biotechnol. 404 Prog. 23 (2007) 42-5.

405 [7] N.J. Darton, N.M. Reis, M.R. Mackley, N.K.H. Slater, Fast cation-exchange 406 separation of proteins in a plastic microcapillary disc., J. Chromatogr. A. 1218 (2011) 140940715.

408 [8] B. Hallmark, F. Gadala-Maria, M.R. Mackley, The melt processing of polymer 409 microcapillary film (MCF), J. Nonnewton. Fluid Mech. 128 (2005) 83-98.

410 [9] S. Bonyadi, M. Mackley, The development of novel micro-capillary film membranes, 411 J. Memb. Sci. 389 (2012) 137-147.

412 [10] I. Mandal, M.J. Townsend, N.J. Darton, S. Bonyadi, N.K.H. Slater, A microporous 413 walled micro-capillary film module for cation-exchange protein chromatography, J. Memb. 414 Sci. 466 (2014) 123-129.

415 [11] N.J. Darton, D. Darling, M.J. Townsend, D.J. McNally, F. Farzaneh, N.K.H. Slater, 416 Lentivirus capture directly from cell culture with Q-functionalised microcapillary film 417 chromatography., J. Chromatogr. A. 1251 (2012) 236-9.

418 [12] M.J. Townsend, D.E. Gruber, M. Kuiper, R.A. Lazar, R.P. Field, R.E. Turner, et al., 419 Functionalized micro-capillary film for the rapid at-line analysis of IgG aggregates in a cell 420 culture bioreactor., MAbs. 7 (2015) 812-819.

421 [13] G.E. McCreath, R.O. Owen, D.C. Nash, H.A. Chase, Preparation and use of ion422 exchange chromatographic supports based on perfluoropolymers, J. Chromatogr. A. 773 423 (1997) 73-83. 

exchange capacity of anion-selective membranes, Int. J. Hydrogen Energy. 39 (2014) 50545062.

[15] S. Lowell, J.E. Shields, Powder Surface Area and Porosity, in: Springer Netherlands, Dordrecht, 1984: pp. 11-13.

[16] NIST Mass Spec Data Center, S.E. Stein, director, "Infrared Spectra" in NIST W.G. Mallard, National Institute of Standards and Technology, Gaithersburg MD, 20899, http://webbook.nist.gov, (retrieved June 12, 2016).

[17] W. Padgett, W. Hamner, The infrared spectra of some derivatives of 1, 3, 5-triazine, J. Am. Chem. Soc. 80 (1958) 803-808.

[18] GE Healthcare Life Sciences. "DEAE Sepharose Fast Flow, 500 ml." in GE Healthcare Life Sciences, http://www.gelifesciences.com, (retrieved August 17, 2016)

[19] GE Healthcare Life Sciences. “Capto DEAE, 100 mL” in GE Healthcare Life Sciences, http://www.gelifesciences.com, (retrieved August 17, 2016)

[20] Pall. “Acrodisc ${ }^{\circledR}$ Units with Mustang® Q and S Membranes” in Pall, http://www.pall.com, (retrieved August 22, 2016) Ligands, in: Chem. Soc. Spec. Pub. No. 6, 1957.

[22] H.-C. Liu, J.R. Fried, Breakthrough of lysozyme through an affinity membrane of cellulose-cibacron blue, AIChE J. 40 (1994) 40-49. resistance to mass transfer as causes of nonideality in chromatography, Chem. Eng. Sci. 50 $447 \quad$ (1995) 3869-3882.

[24] M. Phillips, J. Cormier, J. Ferrence, C. Dowd, R. Kiss, H. Lutz, et al., Performance of a membrane adsorber for trace impurity removal in biotechnology manufacturing, J. Chromatogr. A. 1078 (2005) 74-82.

[25] Brahma, A., Mandal, C., Bhattacharyya, D. (2005). Characterization of a dimeric unfolding intermediate of bovine serum albumin under mildly acidic condition. Biochimica et Biophysica Acta - Proteins and Proteomics, 1751 (2), 159-169.

[26] World Health Organization. (2013). Guidelines on the quality, safety, and efficacy of biotherapeutic protein products prepared by recombinant DNA technology. (WHO Technical Report Series 813, Replacement of Annex 3).

457 http://www.who.int/biologicals/biotherapeutics/en/, (retrieved August 31, 2016) 


\section{Figure captions}

461 Fig. 1: Chemical route to modify MMCFs into weak anion exchangers using DEAE as the chemical ligand. Coupling of cyanuric chloride to the membrane was performed and maintained in ice cold condition until addition of DEAE.

Fig. 2: (A) SEM image of an MMCF cross section taken at the Cambridge Advanced Imaging Centre (CAIC) at an acceleration voltage of $5.0 \mathrm{kV}$ using FEI Verios 460. Membranes were freeze dried with liquid nitrogen in a Quorum K775X freeze dryer (Laughton, UK), fractured to obtain clean edges and gold coated. The average capillary bore diameter was calculated assuming a circular cross-section of same area using Image $\mathrm{J}$ and found to be $351 \pm 42 \mu \mathrm{m}$. (B) Cross-sectional representation of an MMCF column module. (C) Schematic representation of an MMCF column encased in a FEP $8 \mathrm{~mm}$ tube fitted with PTFE adaptors.

Fig. 3: (A) Nitrogen adsorption isotherm at $77.4 \mathrm{~K}$ of MMCF membrane sample of mass 0.09 g.(B)

472 Mercury porosimetry pore size distribution of a sample of mass $0.36 \mathrm{~g}$. Smaller pores were attributed

473 to the pores within the matrix of the membrane whereas the larger apparent pores corresponded to the 474 capillary bores, macrovoids and other membrane defects.

475 Fig. 4: FTIR spectra of unmodified and DEAE modified MMCFs normalised to the common $\mathrm{CH}_{2}$ 476 vibrational peak at $2852 \mathrm{~cm}^{-1}$ and offset vertically. Triazine in-plane ring vibrations $\left(1578 \mathrm{~cm}^{-1}\right)$ and 477 the secondary N-H amine bond $\left(1547 \mathrm{~cm}^{-1}\right)$ of DEAE coupled to the MMCF are shown in bold.

478 Fig. 5: (A) Static adsorption isotherm of BSA onto MMCF-DEAE. (B) Adsorption isotherm of BSA 479 on MMCF-DEAE in flow (dynamic) condition. Langmuir fit for (A) $\mathrm{q}_{\max }=12.4 \mathrm{mg} / \mathrm{mL}$ adsorbent 480 and $\alpha=0.36 . \mathrm{R}^{2}=0.98$. Langmuir fit for $(\mathrm{B}) \mathrm{q}_{\max }=8.2 \mathrm{mg} / \mathrm{mL}$ adsorbent and alpha $=0.34 . \mathrm{R}^{2}=$ 481 0.99. Experiments were repeated in triplicate and the standard deviation is shown. The binding 482 reported was normalised to the column volume of $1.06 \mathrm{~mL}$.

Fig. 6: (A) Time course experiment measuring the mass of BSA bound onto an MMCF-DEAE membrane with an initial loading solution of $1 \mathrm{mg} / \mathrm{mL}$ BSA solution in Tris-HCl. (B) First 8 hours of 485 the loading. A linear fit was performed and found to agree well with experimental data, $R^{2}=0.98$.

486 Experiments were repeated in triplicate and the standard deviation is shown.

487 Fig. 7: Effect of buffer $\mathrm{pH}$ on the binding of BSA onto an MMCF-DEAE column. (A) Breakthrough 488 curves during continuous loading of BSA (10 mg/mL). (B) Elution profile of the bound protein. (C) Mass of BSA eluted normalised to column volume. Experiments were repeated in triplicate and the standard deviation is reported. 
491 Fig. 8: The effect of flowrate on the binding of BSA onto an MMCF-DEAE column. Experiments 492 were repeated in triplicate at flowrates between $0.1 \mathrm{~mL} / \mathrm{min}$ and $10 \mathrm{~mL} / \mathrm{min}$. Only representative 493 chromatograms are shown in (A) and (B). (A) corresponds to the sample loading flowthrough and (B) 494 to the associated elution step. (C) shows the captured amount of BSA in the elution peak relative to 495 the injected amount of BSA (0.5 mg). The standard deviation is reported.

496 Fig. 9: (A) Frontal loading of BSA (5 mg/mL) and lysozyme (5 mg/mL). The running buffer was 20 $497 \mathrm{mM}$ Tris- $\mathrm{HCl}$ at $\mathrm{pH} 7.2$ and elution was done using $1 \mathrm{M} \mathrm{NaCl}$ in running buffer. The experiment was 498 repeated in triplicate and fractions were collected for SDS-PAGE purity assessment. (B) SDS-PAGE 499 gel of the fractions collected tenfold diluted. Lanes $\mathrm{M}$ on either side of the gel correspond to the 500 molecular weight markers. Lane A is the pure lysozyme control $(0.1 \mathrm{mg} / \mathrm{mL})$, lane B the BSA control $501(0.1 \mathrm{mg} / \mathrm{mL})$ and lane $\mathrm{AB}$ is a mixture of both. Lanes 1 and 2 are fractions collected during the load 502 step. Lane 3 has a sample of the wash step and lanes 4-7 correspond to the elution of bound protein.

503 Fig. 10: $100 \mu \mathrm{L}$ injection of proteins onto an MMCF-DEAE column at a flowrate of $1 \mathrm{~mL} / \mathrm{min}$. A 504 two-step elution is specified at $0.25 \mathrm{M} \mathrm{NaCl}$ and $1 \mathrm{M} \mathrm{NaCL}$. (A) BSA injection (5 mg/mL) (B) 505 Injection of herring sperm DNA (0.25 mg/mL), (C) Mixture of BSA (5 mg/mL) and fish DNA (0.25 $506 \mathrm{mg} / \mathrm{mL}$ ). Experiments were repeated in triplicate. UV measurements were made at a wavelength of $507 \quad 254 \mathrm{~nm}$. 